\title{
Development of radio acoustic sounding system (RASS) with Gadanki MST radar - first results
}

\author{
T. V. Chandrasekhar Sarma ${ }^{1}$, D. Narayana Rao ${ }^{1}$, J. Furumoto ${ }^{2}$, and T. Tsuda ${ }^{2}$ \\ ${ }^{1}$ National Atmospheric Research Laboratory, Gadanki 517 112, India \\ ${ }^{2}$ Research Institute for Sustainable Humanosphere, Kyoto University, Uji, Kyoto 611-0011, Japan
}

Received: 19 March 2008 - Revised: 14 May 2008 - Accepted: 14 May 2008 - Published: 1 September 2008

\begin{abstract}
A high-power acoustic exciter was designed and developed for the Gadanki MST Radar to facilitate observations in the Radio Acoustic Sounding System (RASS) mode. Sweep range of acoustic signal frequencies was set to $94-125 \mathrm{~Hz}$ so as to satisfy Bragg matching condition for temperature range of $-90^{\circ}-40^{\circ} \mathrm{C}$ between surface and the tropopause (about $17 \mathrm{~km}$ ). Raytracing of acoustic wave propagation was used to predict the antenna beam directions along which optimum RASS echoes could be obtained. During the RASS observation period of about $18 \mathrm{~h}$ on 23-24 July 2006 height profiles of atmospheric virtual temperature were obtained between $1.5 \mathrm{~km}$ and $10 \mathrm{~km}$ and occasionally up to $14 \mathrm{~km}$. In comparison with the three simultaneous radiosonde launches, RASS derived temperature profiles had the r.m.s. discrepancy of about $1 \mathrm{~K}$, although deviation of the RASS results sometimes appeared when the radial wind velocity was not fully available for the correction of apparent sound speed. This study has successfully demonstrated capability of the RASS application with the Gadanki MST radar, which will be used for continuous monitoring of the temperature profiles in the troposphere and lower stratosphere region in the tropics.
\end{abstract}

Keywords. Atmospheric composition and structure (Instruments and techniques)

\section{Introduction}

Profiling of atmospheric temperature is done using in situ as well as remote sensing techniques. Radiosonde measurement, which is the standard in situ technique being used worldwide, generates height profiles of atmospheric temperature with a fine altitude resolution $(\sim 30 \mathrm{~m})$; the time resolution is, however, coarse - on the order of a few

Correspondence to: T. V. Chandrasekhar Sarma

(tvcsarma@narl.gov.in) hours. Ground-based remote sensing techniques include Radio Acoustic Sounding System (RASS), Raman Lidar and passive Microwave Radiometry. Raman Lidar technique provides a measurement with fine altitude resolution $(\sim 30 \mathrm{~m})$ but is limited to times of clear sky and night-time operation only. Microwave radiometric temperature profiling provides data in lower tropospheric altitudes but the measurements have a coarse resolution. In contrast, RASS is a groundbased remote profiling technique that is almost all-weather and provides data with high altitude and temporal resolutions upto greater altitudes. An outline of these techniques can be found in Clifford et al. (1994).

RASS uses the effect of temperature on the speed of sound in air as a means to sense the atmospheric temperature. It is the combination of a Doppler radar and an acoustic exciter. The Doppler radar profiles the speed of refractive index perturbations induced by the acoustic source. Over the past four decades RASS has been demonstrated to be a reliable ground-based remote profiling technique to obtain altitude profiles of atmospheric virtual temperature, $T_{v}$ (e.g. Marshall et al., 1972; Bonino et al., 1979; Kon, 1981; Makarova, 1980; Matuura et al.,1986; Peters et al., 1988; May et al., 1990). Using RASS, continuous observations of $T_{v}$ with high temporal resolution have been conducted (e.g. Tsuda et al., 1994; Alexander et al., 2007). Limitations in the use of RASS due to the effects of wind and turbulence have been analyzed by Masuda (1988) and May et al. (1990).

The Gadanki $\left(13.46^{\circ} \mathrm{N}, 79.17^{\circ} \mathrm{E}\right) \mathrm{MST}$ radar is a high power VHF pulsed coherent Doppler radar established for remote probing of atmospheric phenomena in the Mesosphere Stratosphere Troposphere regions (Rao et al., 1995). In order to add the temperature measurement capability to this radar, an acoustic attachment was designed and constructed for observations in the RASS mode. This paper describes the system architecture and experimental parameters used and presents first observations. 


\section{RASS system at Gadanki}

\subsection{Basic principle of RASS}

RASS consists of a wind profiler and a colocated acoustic source. An outline of the functioning of the wind profiler and turbulence echo measurement followed by that of RASS is given below.

A wind profiler is a pulsed coherent Doppler radar working in either VHF or UHF band of the electromagnetic spectrum. Electromagnetic pulses are transmitted by the radar along antenna beam directions which are typically within $\mp 20^{\circ}$ of the zenith direction. Received signals are downconverted and detected by using signals from the same reference local oscillator (LO) that was used to generate the transmitted signal. The time rate-of-change of the phase of the received signals from each altitude gives the Doppler shift which is proportional to the line-of-sight velocity of the medium at that altitude. Due to the phase-coherent nature of the reference, these radars are known as coherent radars.

Backscatter of transmitted wave is obtained primarily from atmospheric radio refractive index fluctuations due to inertial range turbulence scale sizes which are one-half the transmitted wavelength; the phenomenon is known as Bragg scattering. A detailed description of the technique and scattering mechanisms can be found in the literature (cf. Woodman and Guillen, 1974; Balsley and Gage, 1980). These turbulence fluctuations drift with the background wind and are used by the wind profiler as a tracer of the background wind. By determining the line-of-sight velocity along three non-coplanar directions, three-dimensional wind-vector is constructed at each altitude of interest under an assumption of a homogeneous wind velocity field over the volume encompassed by the antenna beams.

In RASS system the acoustic source is used to modulate atmospheric refractive index fluctuations so that conditions for Bragg scattering are satisfied. As the atmospheric temperature lapse rate with altitude is about $6-10 \mathrm{~K} \mathrm{~km}^{-1}$, the speed of sound which is dependent on the ambient temperature decreases with altitude. Consequently, to satisfy the Bragg condition of scattering, a different frequency of sound is required for this purpose for each altitude of interest. Therefore, range of acoustic frequencies to be transmitted is computed for which Bragg matching occurs over the entire altitude range of interest. In addition, to obtain useful echoes it is essential that the radar antenna beam direction is normal to the acoustic wavefronts propagating away from the radar. Otherwise, the backscatter may fall outside the antenna array and result in significant or total loss of received echo power.

The wind profiler is used to measure speed of propagation of acoustic wavefronts, $C_{a}\left(\mathrm{~m} \mathrm{~s}^{-1}\right)$ which is related to ambient temperature $T(\mathrm{~K})$,

$T=\left(\frac{C_{a}}{k_{h}}\right)^{2}$.
The constant $k_{h}\left(\mathrm{~J} \mathrm{~K}^{-1} \mathrm{~kg}^{-1}\right)$ in Eq. (1) is given by

$k_{h}=\left(\frac{\gamma R}{M}\right)^{1 / 2}$,

where $\gamma \quad(1.4), \quad R\left(8314.472 \mathrm{~J} \mathrm{~K}^{-1} \mathrm{kmol}^{-1}\right) \quad$ and $\quad M$ $\left(28.964 \mathrm{~kg} \mathrm{kmol}^{-1}\right)$ are ratio of specific heat at constant pressure to specific heat at constant volume, universal gas constant and mean molecular weight of dry air respectively. For a dry atmosphere $k_{h}$ works out to be 20.047 . RASS determines ambient virtual temperature $T_{v}$, which is defined as the temperature that dry air would have if its pressure and density were equal to those of a given sample of moist air. Absolute temperature $T$ and $T_{v}$ are related as,

$T_{v}=(1+0.608 q) T$

where $q\left(\mathrm{~kg} \mathrm{~kg}^{-1}\right)$ is the specific humidity which is normally the highest near the surface and decreases exponentially with altitude. Tsuda et al. (1994) show that under a sub-tropical condition the difference between $T$ and $T_{v}$ at $1.5 \mathrm{~km}$ is about $2.0 \mathrm{~K}$ and becomes very small at around $4 \mathrm{~km}$.

A schematic of the RASS system implemented with Gadanki MST Radar is shown in Fig. 1. The radar system is shown on the left and the acoustic part is shown on the right side. The specifications of the radar system and acoustic system are shown in Table 1. The antenna array consists of two sets of Yagi-elements - one aligned along EW and the other along NS plane and is capable of steering the antenna beam within an angular region of $\pm 20^{\circ}$ with respect to zenith in these planes. The zenith beam formed by NS aligned dipoles is designated as $Z x$ and that formed by EW aligned dipoles is designated as $Z y$.

Taking a temperature range of $-90^{\circ} \mathrm{C}$ to $40^{\circ} \mathrm{C}$ and the radar wavelength of $5.66 \mathrm{~m}$, the range of acoustic frequencies for measurements in the troposphere and lower stratosphere is approximately $94-125 \mathrm{~Hz}$. Corresponding Doppler shift is in the range of $-94 \mathrm{~Hz}$ to $-125 \mathrm{~Hz}$. Negative Doppler shifts indicate propagation away from the radar.

The measured sound speed from the wind profiler is the apparent speed with respect to the radar. It is biased by the background wind field. Therefore, wind speed in the direction of propagation of the acoustic waves is to be subtracted to obtain true speed of sound.

\subsection{Offset of second Local Oscillator (LO) frequency}

In the radar receiver chain, after quadrature detection, the complex time series of backscattered signal for each range gate due to successive transmitted pulses is formed by digitisation and decoding for coded transmission (also known as pulse compression) and subjected to further processing.

Data samples from individual range gates are coherently integrated to improve the signal to noise ratio (SNR). The maximum Doppler shift $F_{d_{-} \max }$ that can be determined 


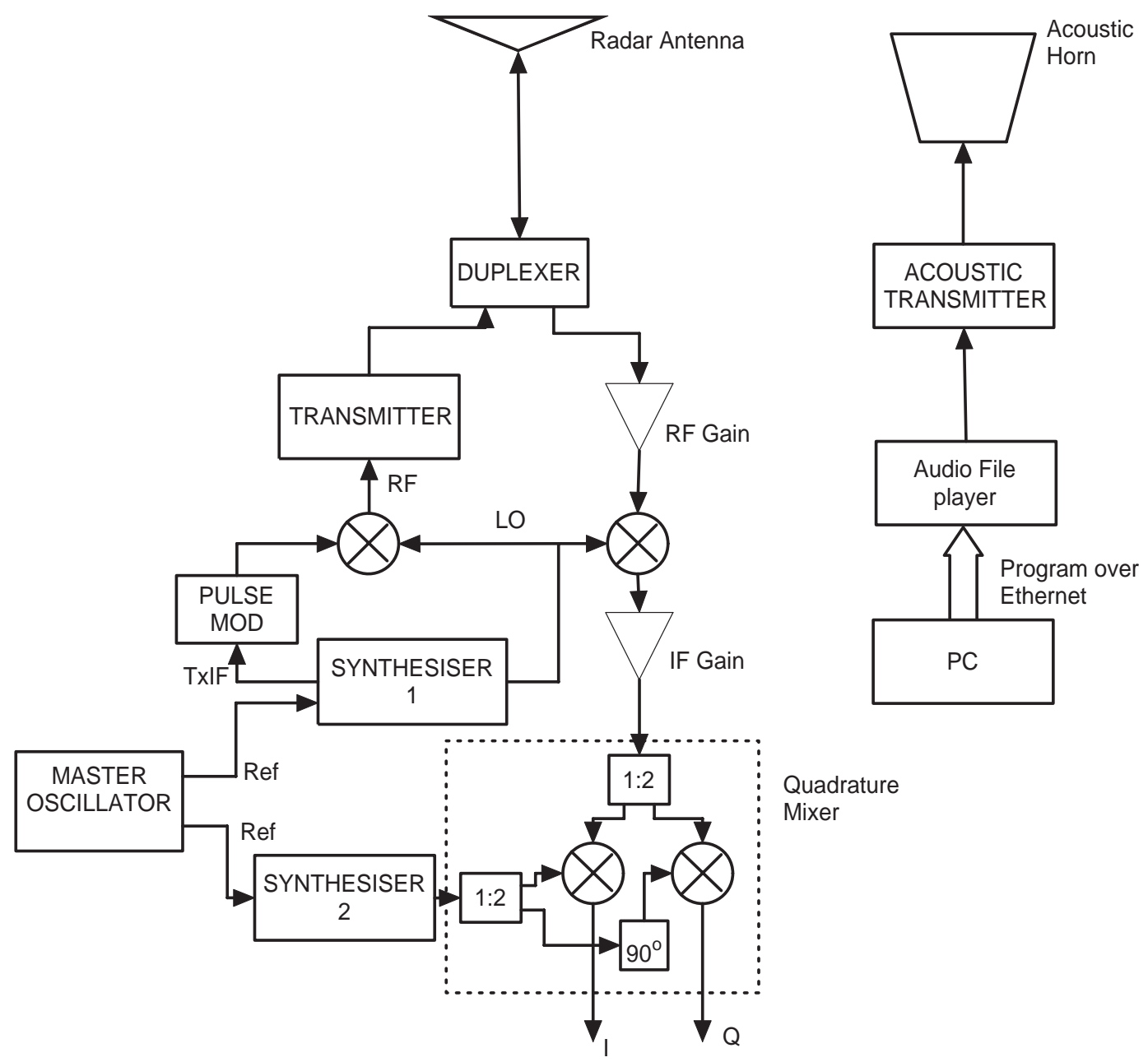

Fig. 1. Simplified block schematic of Radio Acoustic Sounding System.

unambiguously depends on the inter-pulse period (IPP) and the number of coherent integrations (NCI) as,

$F_{d_{-} \max }= \pm \frac{1}{2 \times I P P \times N C I}$.

The backscattered echo experiences a Doppler shift due to the speed of sound and the background wind component in the beam direction. The range of radial wind speeds is typically around $10-20 \mathrm{~m} \mathrm{~s}^{-1}$, whereas the speed of sound is around $300 \mathrm{~m} \mathrm{~s}^{-1}$ corresponding to Doppler shifts in the range of about $3-6 \mathrm{~Hz}$ and $100 \mathrm{~Hz}$, respectively, for a $50 \mathrm{MHz}$ radar. As the sound propagation is away from the radar, corresponding Doppler shift is always negative and is around $-100 \mathrm{~Hz}$. For the observation of CAT, IPP and NCI are chosen such that $F_{d_{-} \max }$ is around $\pm 8 \mathrm{~Hz}$. In order to accommodate the acoustic echo without aliasing, $F_{d_{-} \max }$ needs to be increased to a little over $\pm 100 \mathrm{~Hz}$. This is achieved by reducing NCI as in practice the value of IPP is fixed based on requirement of maximum unambiguous range and the maximum duty ratio limitation on the radar transmitters, thereby reducing the SNR. To obviate this difficulty, it would be desirable to obtain the acoustic echo and turbulent echo separately by shifting the second LO with another synthesizer than that used for generating the transmit IF.

For this purpose two synthesizers are used as shown in Fig. 1. Synthesiser-1 is used to generate the Transmit IF for further pulse modulation and transmission and synthesizer-2 is used to generate the shifted LO-2 frequency required for beating down the acoustic echo. The output frequency of synthesizer-2 was manually switched between two frequencies: $5 \mathrm{MHz}$ and $4.999890 \mathrm{MHz}$ for regular wind profiling mode and RASS mode, respectively. When the LO-2 frequency is at $5 \mathrm{MHz}$, it is the normal mode of operation of the radar and is used to record the CAT echoes. To obtain the echoes due to sound speed, LO-2 is offset as mentioned above, resulting in the Doppler spectrum that is cetered on $-110 \mathrm{~Hz}$ to be shifted to around $0 \mathrm{~Hz}$. This offset is later added to the mean Doppler shift due to acoustic echo $\left(F_{d_{-} a}\right)$ as discussed in Sect. 3.3. A computer-controlled switching mechanism will be used for further experiments. The 
Table 1. Specifications of the Gadanki MST radar/RASS system.

\begin{tabular}{ll}
\hline \multicolumn{2}{l}{ Radio system (Monostatic pulse Doppler radar) } \\
\hline Location & Gadanki $\left(13.46^{\circ} \mathrm{N}, 79.17^{\circ} \mathrm{E}\right)$ \\
RF Frequency & $53 \mathrm{MHz}$ \\
IF Frequency & $5 \mathrm{MHz}$ \\
Output power (peak) & $2.5 \mathrm{MW}$ \\
Antenna aperture & $126 \mathrm{~m} \times 126 \mathrm{~m}$ \\
Antenna beam directions & within $\mp 20^{\circ}$ at $1^{\circ}$ step along E-W and N-S planes \\
Pulse width & $1-32 \mu \mathrm{s}$ \\
Pulse repetition frequency & Upto $5 \mathrm{kHz}$ \\
Maximum duty ratio & $2.5 \%$ \\
Pulse compression & Biphase coding \\
No. of Coherent integration & User defined \\
No. of incoherent integration & User defined \\
FFT points & Max 512 for online spectrum \\
\hline Acoustic system & \\
\hline Signal generation & Network audio receiver ONKYO NC-500 \\
Frequency & $90-130 \mathrm{~Hz}$ \\
Acoustic power & $140 \mathrm{dBA}$ \\
Antenna & Hyperbolic horn \\
Pulse repetition period & Programmable \\
Pulse width & Programmable \\
\hline
\end{tabular}

switching of LO-2 frequency allows integrating the radar returns coherently higher number of times compared to the full bandwidth operation thereby increasing the SNR.

\subsection{Acoustic transmitter: design and performance}

A pilot acoustic attachment to MST Radar has been developed and installed. The acoustic generator was configured using commercial off-the-shelf components for signal generation, signal amplification and transmission. A schematic of the acoustic signal generation system is shown in Fig. 2. It may be noted that the radar and acoustic generator operate independently. However, synchronisation between the two is not required.

Acoustic data files in the standard WAVE file format (cf. http://en.wikipedia.org/wiki/WAV) are generated on the PC and are transferred over Ethernet to ONKYO NC500 network audio receiver, which converts the digital data to analog voltages. The use of PC-based signal generation provides a high degree of flexibility in the waveform design. Further, the advantage of Ethernet-based analog-to-digital conversion facilitates placement of the acoustic exciter at any chosen location, limited only by the reach of the network. These analog voltages are driven by a pre-amplifier Imagenics UBC-150 over $120 \mathrm{~m}$ Unitronic LiYCY $(0.75 \mathrm{sqmm} \times 4)$ cables to audio power amplifiers Crown CL2 located in the antenna field. Each of the power amplifiers drives a pair of $18^{\prime \prime}$ subwoofers Ahuja L18-SW650 which have a power handling capability of upto $650 \mathrm{Wrms}$.
Initially a pair of acoustic horns, each with two subwoofers, has been developed. Figure 3 shows the location of the horns deployed at the center of the MST Radar antenna array.

\subsubsection{Acoustic attachment design}

A wooden horn was fabricated whose vertical cross-section approximates a hyperbolic curve given by the following equation (Olson, 1957; Adachi, 1996):

$S=S_{0}\left(\cosh \frac{2 \pi f_{c}}{c_{s}} x+\alpha \sinh \frac{2 \pi f_{c}}{c_{s}} x\right)^{2}$.

Here,

$S=$ Cross-section at a distance $x$ from the mouth

$S_{0}=$ Cross-section at the mouth

$f_{c}=$ Lower cutoff frequency

$c_{s}=$ speed of sound

$\alpha=$ a coefficient

Using $S_{0}=0.25 \mathrm{~m}, f_{c}=75 \mathrm{~Hz}, \alpha=0.6$, and $c_{s}=330.0 \mathrm{~m} \mathrm{~s}^{-1} \mathrm{a}$ hyperbolic curve is drawn based on which a horn was constructed using linear approximation to the curve. A crosssection of the horn is shown in Fig. 4 (Adachi, 1996). 


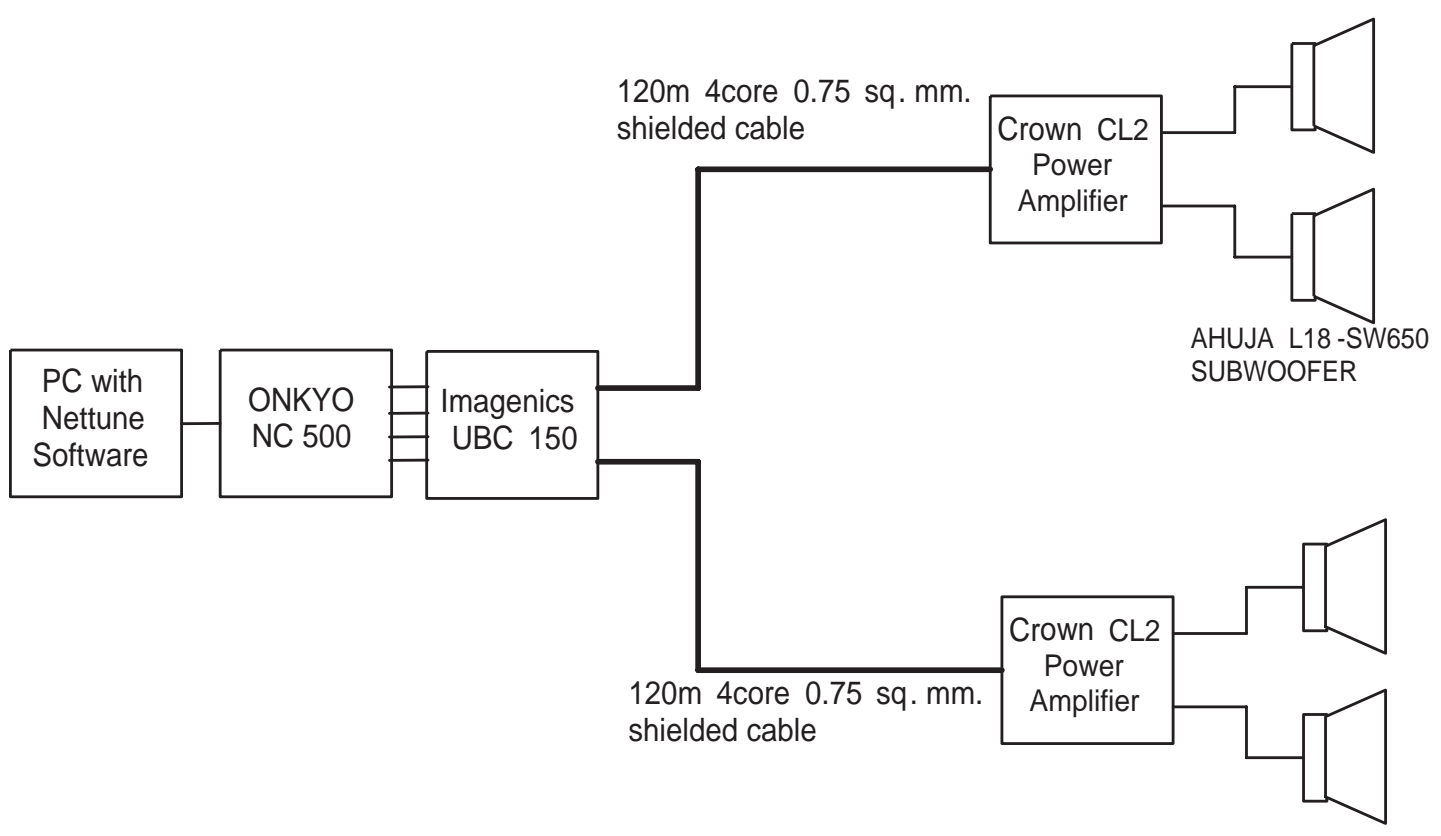

Fig. 2. Block diagram of the acoustic exciter.

Table 2. Input electrical power Vs output SPL (at $100 \mathrm{~Hz}$ ).

\begin{tabular}{|c|c|c|c|c|c|}
\hline \multicolumn{2}{|c|}{ Subwoofer $1(8 \Omega)$} & \multicolumn{2}{|c|}{ Subwoofer $2(8 \Omega)$} & \multirow{2}{*}{$\begin{array}{c}\text { Total RMS } \\
\text { power } \\
\text { (watt) }\end{array}$} & \multirow{2}{*}{$\begin{array}{l}\text { SPL } \\
\text { (dB) }\end{array}$} \\
\hline $\begin{array}{l}\text { Vpp } \\
\text { (volt) }\end{array}$ & $\begin{array}{l}\text { RMS Power } \\
\text { (watt) }\end{array}$ & $\begin{array}{l}\text { Vpp } \\
\text { (volt) }\end{array}$ & $\begin{array}{l}\text { RMS Power } \\
\text { (watt) }\end{array}$ & & \\
\hline 38.0 & 22.56 & 35.00 & 19.14 & 41.70 & 129.7 \\
\hline 64.0 & 64.00 & 64.00 & 64.00 & 128.00 & 134.5 \\
\hline 88.0 & 121.00 & 86.00 & 115.56 & 236.56 & 136.6 \\
\hline 112.0 & 196.00 & 112.00 & 196.00 & 392.00 & 138.4 \\
\hline 136.0 & 289.00 & 136.00 & 289.00 & 578.00 & 139.7 \\
\hline 164.0 & 420.25 & 164.00 & 420.25 & 840.50 & 140.4 \\
\hline
\end{tabular}

\subsubsection{Measurement of Horn output power and Frequency response}

The output power and frequency response of the horn were measured. Larson Davis Model 2900B level meter along with Brüel and Kjaer 4192 microphone was used for measuring the sound pressure level at the output of the horn.

Horns were excited with a frequency of $100 \mathrm{~Hz}$. The sound pressure level (SPL) was measured at several points at the mouth of the horn as shown in Fig. 5. Measurements were done when the peak SPL at the centre was about $140 \mathrm{~dB}$. Further, for different input electrical power levels to the speaker, the SPL was recorded. This is shown in Table 2 and Fig. 6. The input electrical root mean square (rms) power used is about $800 \mathrm{~W}$.

The average acoustic pressure level over the mouth is obtained by taking the average of SPL measurements within
$3 \mathrm{~dB}$ from the peak. The SPL was converted to acoustic power by the following relation.

$P_{a c}=\frac{A \times(\mathrm{SPL})^{2}}{\rho_{0} C_{a}}$.

Here,

$P_{a c}=$ Acoustic power, watt

$A=$ Surface Area, $\mathrm{m}^{2}$

SPL $=$ Sound Pressure Level, $\mathrm{Pa}\left(0 \mathrm{~dB}=20 \times 10^{-6} \mathrm{~Pa}\right.$, the threshold of hearing)

$\rho_{0} C_{a}=$ Characteristic impedance of the medium

$\rho_{0}=$ density of air

$C_{a}=$ speed of propagation of sound $350 \mathrm{~m} \mathrm{~s}^{-1}$.

An electrical to acoustic power conversion efficiency of about $20 \%$ was obtained. 
Table 3. Experimental parameters of MST radar.

\begin{tabular}{|c|c|c|c|c|}
\hline Parameter & Rass mode 1 & Wind mode 1 & Rass mode 2 & Wind mode 2 \\
\hline Pulse Width $(\mu \mathrm{s})$ & 1 & 1 & 16 & 16 \\
\hline Coding used & None & None & $\begin{array}{c}\text { 16-bit, } 1 \mu \mathrm{s} \text { baud } \\
\text { Biphase Complementary }\end{array}$ & $\begin{array}{c}\text { 16-bit, } 1 \mu \text { s baud } \\
\text { Biphase Complementary }\end{array}$ \\
\hline Range resolution (m) & 150 & 150 & 150 & 150 \\
\hline Inter Pulse Period $(\mu \mathrm{s})$ & 250 & 250 & 1000 & 1000 \\
\hline Beam sequence & $\begin{array}{l}\text { Chosen based on } \\
\text { ray tracing result }\end{array}$ & $\begin{array}{c}20^{\circ} \mathrm{E}, 20^{\circ} \mathrm{W}, Z y^{\mathrm{a}}, \\
Z x^{\mathrm{a}}, 20^{\circ} \mathrm{N}, 20^{\circ} \mathrm{S}\end{array}$ & $\begin{array}{l}\text { Chosen based on } \\
\text { ray tracing result }\end{array}$ & $\begin{array}{c}20^{\circ} \mathrm{E}, 20^{\circ} \mathrm{W}, Z y, \\
Z x, 20^{\circ} \mathrm{N}, 20^{\circ} \mathrm{S}\end{array}$ \\
\hline No. of coherent integrations & 50 & 256 & 24 & 64 \\
\hline No. of FFT points & 256 & 512 & 256 & 512 \\
\hline No. of online incoherent integrations & None & None & None & None \\
\hline Start of observation range window & $1.5 \mathrm{~km}$ & $1.5 \mathrm{~km}$ & $3.6 \mathrm{~km}$ & $3.6 \mathrm{~km}$ \\
\hline No. of range bins & 150 & 150 & 150 & 150 \\
\hline Second LO offset frequency & $-110 \mathrm{~Hz}$ & $0 \mathrm{~Hz}$ & $-110 \mathrm{~Hz}$ & $0 \mathrm{~Hz}$ \\
\hline Time duration & $\sim 10 \mathrm{~min}$ & $\sim 10 \mathrm{~min}$ & $\sim 10 \mathrm{~min}$ & $\sim 15 \mathrm{~min}$ \\
\hline
\end{tabular}

a $Z x$ and $Z y-$ Zenith beams formed using N-S and E-W dipoles, respectively.

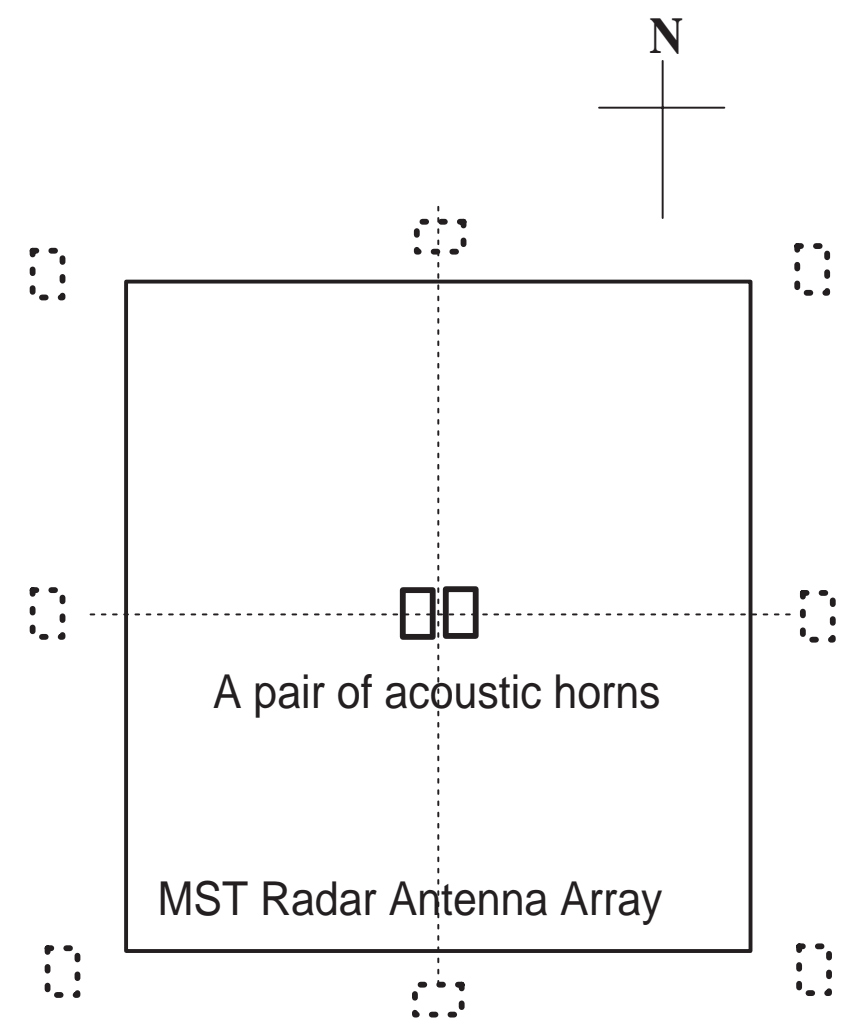

Fig. 3. A pair of horns were located at the center of the MST Radar antenna array (solid rectangles). Proposed acoustic horns are shown on the periphery with broken line.

Frequency response of the horn was measured by making SPL measurements in $\mathrm{dB}$ at individual frequencies in the range $70-140 \mathrm{~Hz}$ at $1 \mathrm{~Hz}$ interval. The input electrical power level to the subwoofers in the horn was maintained
Table 4. Parameters of acoustic exciter.

\begin{tabular}{ll}
\hline Frequency range & $94-125 \mathrm{~Hz}$ \\
Mode of Frequency sweep & Linear FM chirp \\
Duty ratio & $4 \mathrm{~s} \mathrm{ON}, 2 \mathrm{~s}$ OFF \\
Sound pressure level of each horn & $140 \mathrm{~dB}$ \\
No. of horns used & 2 \\
Location of horns & Center of MST Radar antenna array \\
\hline
\end{tabular}

at 317.0 Wrms. At each frequency an 8-s averaging interval with a linear weighting curve (Brüel and Kjaer application note ${ }^{1}$ ) was used. Results of the frequency response are shown in Fig. 7. The frequency response was recorded at two output levels viz., at about $130 \mathrm{~dB}$ and $140 \mathrm{~dB}$. It is observed that in the frequency range $90-130 \mathrm{~Hz}$ the frequency response is almost flat with higher power output near $90 \mathrm{~Hz}$. The higher power output of about $2 \mathrm{~dB}$ in the 80 $100 \mathrm{~Hz}$ range was unexpected. Lower frequencies correspond to lower temperatures found at higher altitudes. Therefore, higher power could be of some advantage in obtaining echoes from higher heights.

\section{Description of the RASS experiment at Gadanki}

\subsection{Observation scheme of RASS and turbulence echoes}

The RASS experiment was conducted at Gadanki during the following dates: 30 May 2006, 1-4 June 2006, 29 June 2006, 23-24 July 2006, 27-28 July 2006 and 1-2 August 2006. The specifications of the radar and the acoustic system used

\footnotetext{
${ }^{1}$ Brüel and Kjaer Application Note: http://www.bksv.com/pdf/ Measuring_Sound.pdf.
} 


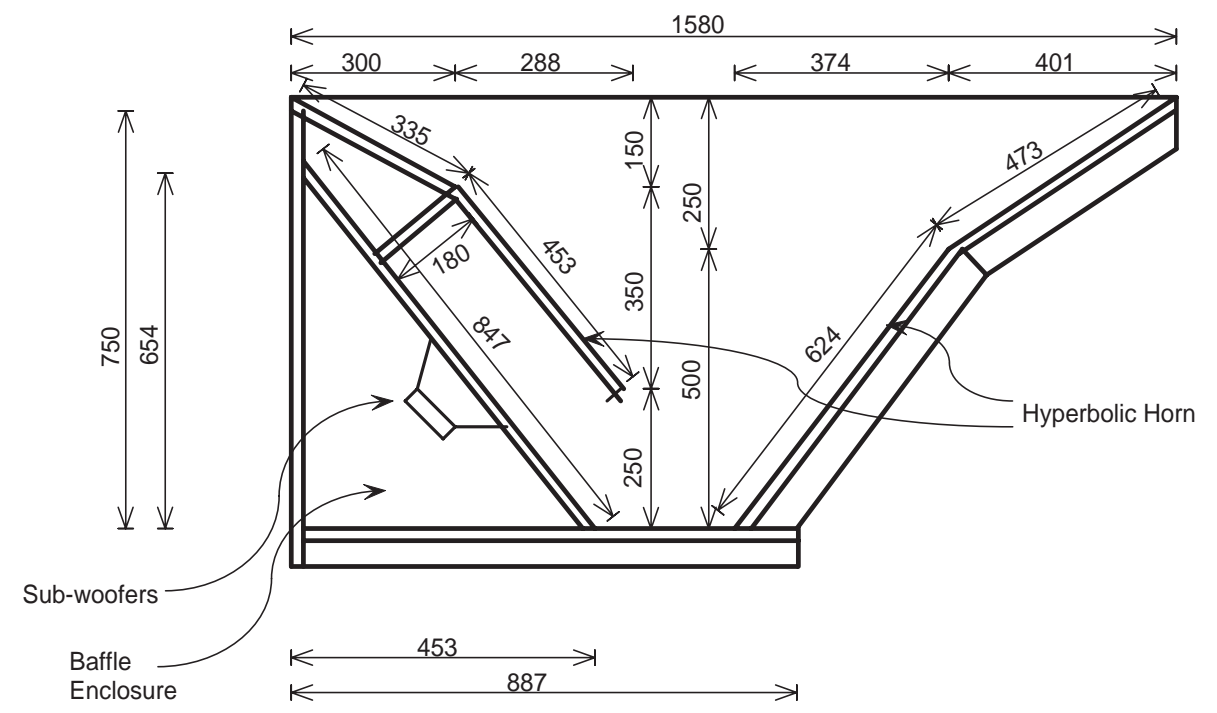

Fig. 4. Cross section of the hyperbolic acoustic horn after Adachi (1996). All dimensions are in mm.

for these experiments are given in Tables 3 and 4, respectively. The acoustic exciter transmitted a linear FM chirp in the band $94-125 \mathrm{~Hz}$ with a duty ratio of $4 \mathrm{~s} \mathrm{ON}$ and $2 \mathrm{~s}$ OFF continuously. Simultaneously GPS radiosondes were launched for comparison of temperature profiles.

The acoustic wavefronts launched by the exciter propagate away from the radar and have hemispherical shape near the exciter. Further on, they encounter the altitude gradient of temperature and the horizontal wind. Due to the temperature decrease with altitude, the speed of propagation decreases resulting in the spherical wavefronts becoming ellipsoidal. Further, the effect of horizontal wind at each altitude distorts the wavefront. Due to these two effects, the antenna beam direction would not be normal to large portions of acoustic wavefronts. This would lead to the backscatter falling outside the antenna array. Ray tracing method as described by Masuda (1988) and extended to three-dimensional analysis by the equations of acoustic ray propagation (Warshaw, 1980) was used to predict the portions of acoustic wavefronts at different altitudes that would result in the radar backscatter from them to fall within the radar antenna array. The radiosonde readings of wind speed, wind direction and temperature were used for this computation. The results of ray tracing at an altitude are affected by the wind speed, wind direction and the temperature values between the ground-surface and that level. As the radar-derived wind speed and direction values are available only from $1.5 \mathrm{~km}$ onwards, these cannot be used directly for ray tracing. Radiosonde data, being continuous from surface, is therefore more suitable for direct use for this purpose. Based on the ray tracing results two antenna beams were chosen in the direction of Zenith along NS plane $(Z x)$ and $20^{\circ}$ off zenith towards west $\left(20^{\circ} \mathrm{W}\right)$ for observations of acoustic waves. These two beams were also used for the observation of turbulence echoes in addition to $20^{\circ} \mathrm{E}$, $20^{\circ} \mathrm{N}, 20^{\circ} \mathrm{S}$ and $Z y$ as shown in Table 3 .

Wind mode- 1 was used for observations of echoes from CAT from $1.5 \mathrm{~km}$ onwards and in wind mode- 2 from $3.6 \mathrm{~km}$ onwards; rass mode- 1 and rass mode- 2 correspond respectively to the same height regions for recording observations of echoes from the acoustic wavefronts propagating away from the radar. The RASS was operated sequentially in the following modes - rass mode-1, wind mode-1, rass mode-2, wind mode- 2 .

Transmission of $16 \mu$ s coded pulses was done so that better range coverage could be achieved for echoes from acoustic wave fronts. But observations have shown that improvement was not seen. This was probably due to unfavorable wind conditions at higher altitudes.

\subsection{Ray tracing results}

Using the radiosonde data of 23 July 2006, ray tracing results were computed for the EW and NS planes of the antenna array and are shown in Figs. 8 and 9. Figure 8a shows the suitable portions of acoustic wavefronts in the altitude range of interest in the E-W plane. The abscissa denotes the distance from the center of the antenna array; positive values are towards East direction. The angular diverging lines represent the antenna beam directions within the $\pm 20^{\circ}$ range of the antenna array. They are drawn at $2^{\circ}$ step to facilitate choice of the antenna beam direction for RASS measurement. Figure $8 \mathrm{~b}$ shows the power spectrum of the echoes due to acoustics excitation obtained using the $20^{\circ} \mathrm{W}$ antenna beam direction. Similarly Fig. 9a shows the analysis results along the NS plane; positive values on the abscissa are towards North. Figure $9 \mathrm{~b}$ shows the power spectrum of echoes obtained using the vertical beam direction $Z x$. 


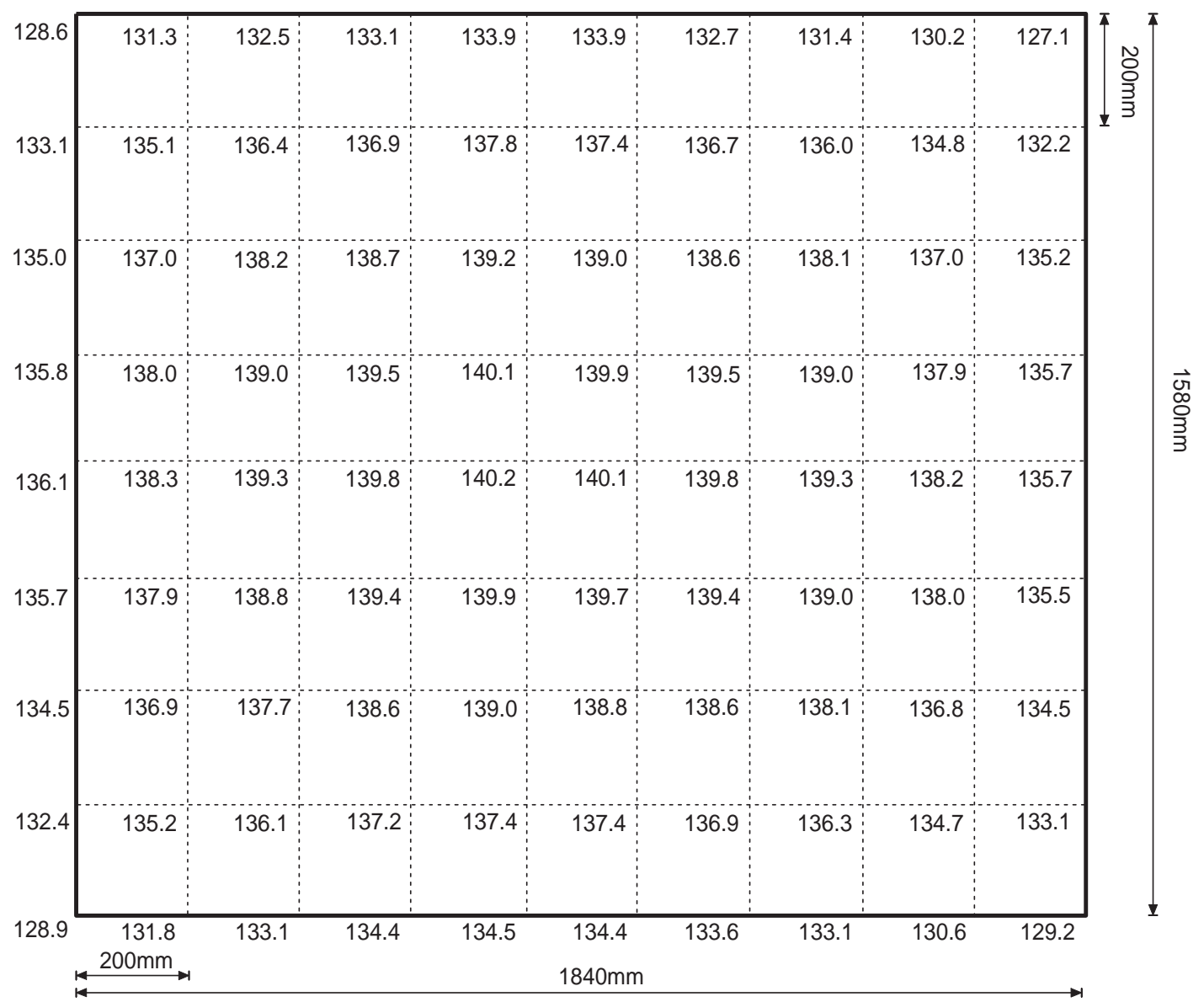

Fig. 5. Sound pressure level (SPL in $\mathrm{dB})$ at the mouth of the horn.

\subsection{Parameter estimation of Doppler spectrum}

An example of Doppler power spectrum of echoes from the acoustic wave fronts is shown in Fig. 10. The shape of the power spectrum due to acoustic wave fronts is generally close to a Gaussian curve. However, occasionally in certain range-bins, power spectrum has a double-humped shape. This phenomenon can be explained as follows. The temperature lapse rate in the troposphere is around $6-10 \mathrm{~K} \mathrm{~km}^{-1}$. In a volume corresponding to the radar antenna beamwidth of $3^{\circ}$ and the radar range resolution of $150 \mathrm{~m}$, the temperature variation is in the range of $0.9-1.5 \mathrm{~K}$. There could be stratification of atmospheric scatterers into horizontal sheets of uniform temperature within a single range resolution volume leading to bimodal spectra.

In each range-bin, Mean Doppler-shift of an N-point power spectrum $S\left(f_{i}\right)$ is obtained by computing the first two central moments $P$ (total power) and $F$ (mean Doppler shift) (Woodman, 1985) after subtraction of the noise level (Hildebrand and Sekhon, 1974).

$$
P=\sum_{i=1}^{N} S\left(f_{i}\right)
$$

$$
F=\frac{1}{P} \sum_{i=1}^{N} f_{i} S\left(f_{i}\right)
$$

Mean Doppler shifts of acoustic echo, $F_{d_{-} a}$, and the echo from turbulence, $F_{d_{-} w}$ were computed in each range bin for the antenna beam direction of $20^{\circ}$ off zenith towards west $\left(20^{\circ} \mathrm{W}\right) . F_{d \_a}$ is shifted by $-110 \mathrm{~Hz}$ to correct for the offset of LO-2 before futher computations. The resultant Doppler shift due to the propagation of the acoustic wavefronts was computed by subtracting $F_{d_{-} w}$ from $F_{d_{-} a}$ to obtain $F_{d}$. The virtual temperature was computed using Eq. (1) along with $C_{a}=F_{d}(\lambda / 2)$ as

$T_{v}=\left(\frac{F_{d} \lambda}{20.047 \times 2}\right)^{2}$.

The virtual temperature derived from RASS was plotted alongside the virtual temperature derived from simultaneous radiosonde observations as shown in Fig. 11. In this figure, RASS derived $T_{v}$ follows closely the radiosonde measurement. The temperature inversion around $5 \mathrm{~km}$ altitude is faithfully captured by the RASS measurement.

The accuracy in the determination of the atmospheric temperature depends on the accuracy of the estimation of 


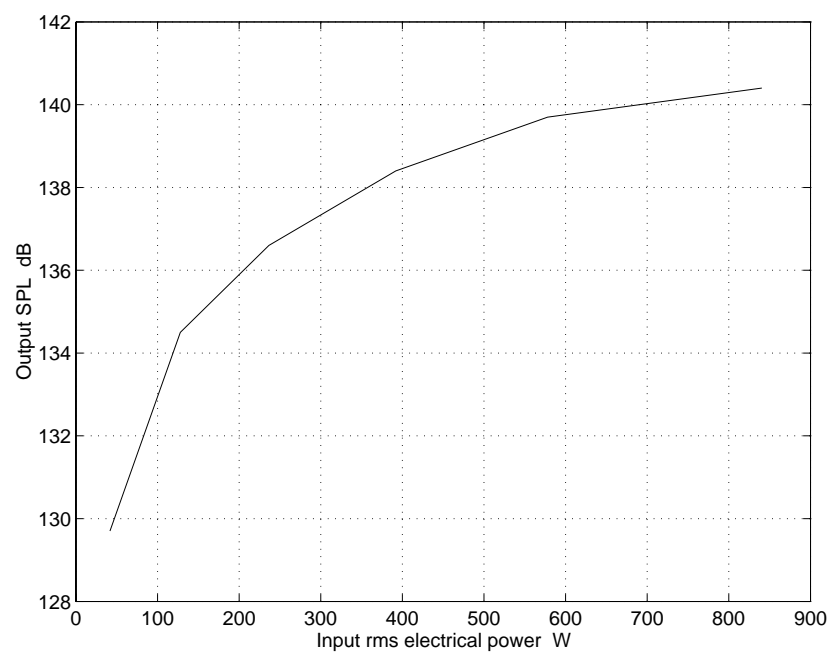

Fig. 6. Input rms electrical power (watt) vs output SPL (dB) response of the acoustic horn.

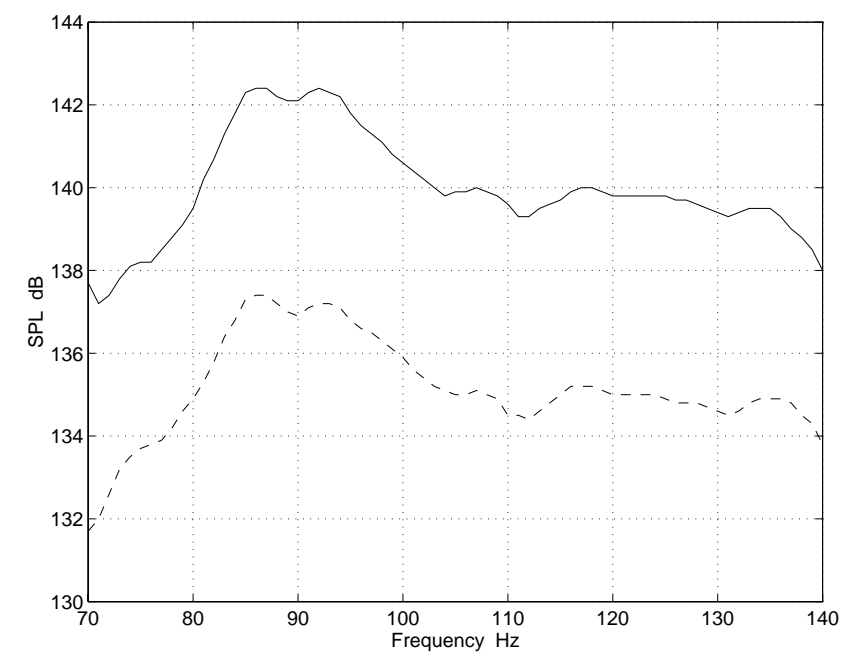

Fig. 7. Frequency response of the acoustic horn developed. Measurements were done at $1116 \mathrm{~W} \mathrm{rms} \mathrm{(solid} \mathrm{line)} \mathrm{and} 265 \mathrm{~W}$ rms (dashed line) input electrical power.

the mean Doppler shift of the echoes from acoustic wavefronts as well as the turbulence. An example of the mean Doppler derived is shown in Figs. 12 and 13, respectively. Mean Doppler shift estimate of the turbulence echo spectrum (Fig. 13) is sometimes in error due to presence of multiple peaks and far away peaks (e.g. as at $3300 \mathrm{~m}$ ) when compared to the spectrum of the acoustic echo which is closer to a Gaussian shape. This will lead to error in the temperature derivation. One of the solutions would be to fit a Gaussian curve to the spectrum which could provide a more realiable estimate of the temperature.

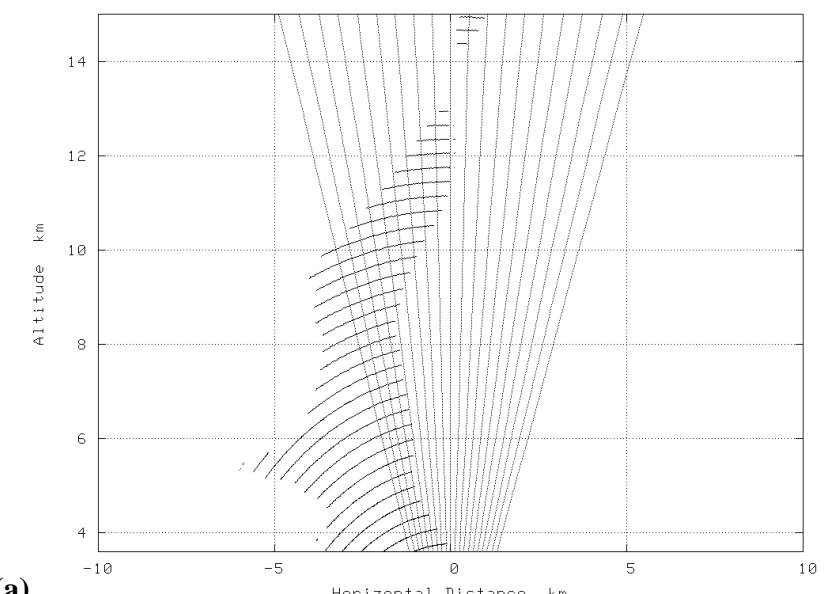

(a)

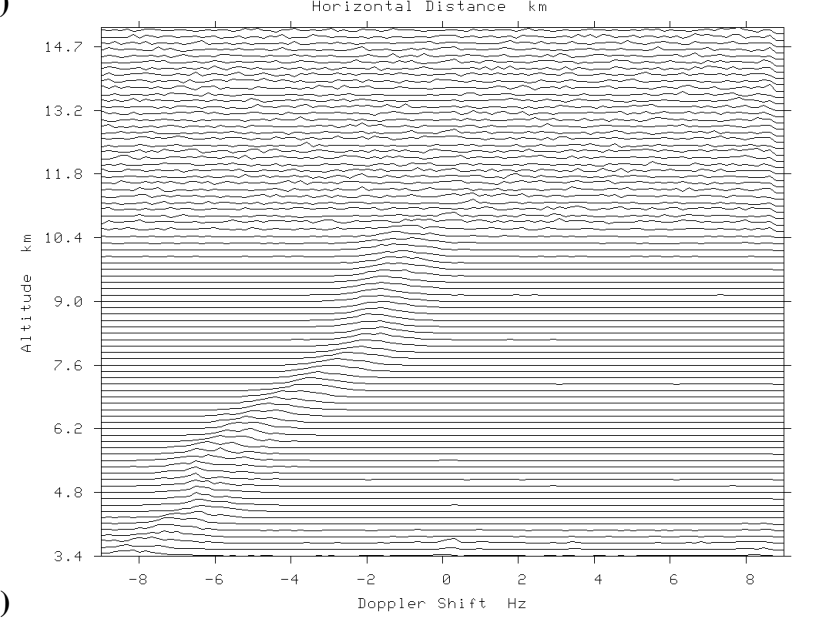

Fig. 8. (a) Portions of acoustic wavefronts from which the backscatter falls on the radar antenna in the E-W plane on 23 July 2006 using the data from radiosonde launched at 17:52 LT. Diverging straight lines are at $2^{\circ}$ step. End lines encompass an angular region of $\mp 20^{\circ}$ corresponding to the beam steering capability of the radar; (b) Doppler power spectrum of $20^{\circ} \mathrm{W}$ antenna beam (15:53:28 LT).

\section{Characteristics of temperature profiles}

Figure 14 shows successive profiles of virtual temperature from the RASS experiment in comparison with the radiosonde results launched at 17:52 LT and 23:33 LT. The $T_{v}$ profiles shown were obtained from data of about $11 \mathrm{~h}$ recorded between 15:50 LT on 23 July and 02:40 LT on 24 July 2006. These profiles are separated by about $25 \mathrm{~min}$. The height coverage of the retrieved $T_{v}$ profiles using the $20^{\circ} \mathrm{W}$ antenna beam is up to $10 \mathrm{~km}$. By combining the results obtained occasionally from the $Z x$ beam they were extended upto $14 \mathrm{~km}$. The $T_{v}$ profiles compare well with the radiosonde derived results. Further, it can be seen that there is a good consistency between the successive profiles. From these profiles, it might be possible to discern atmospheric wave activity from the propagation of phase manifested as fine temperature perturbations around the mean temperature. 


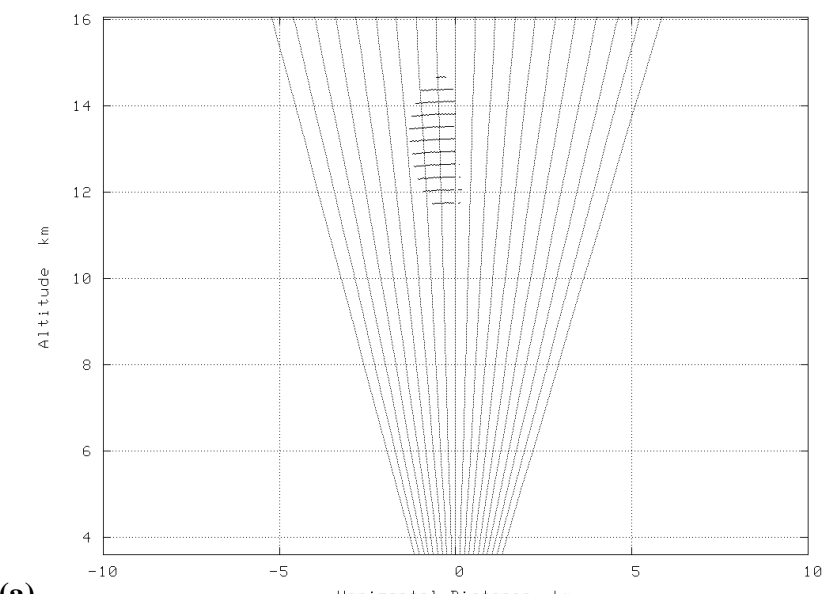

(a)

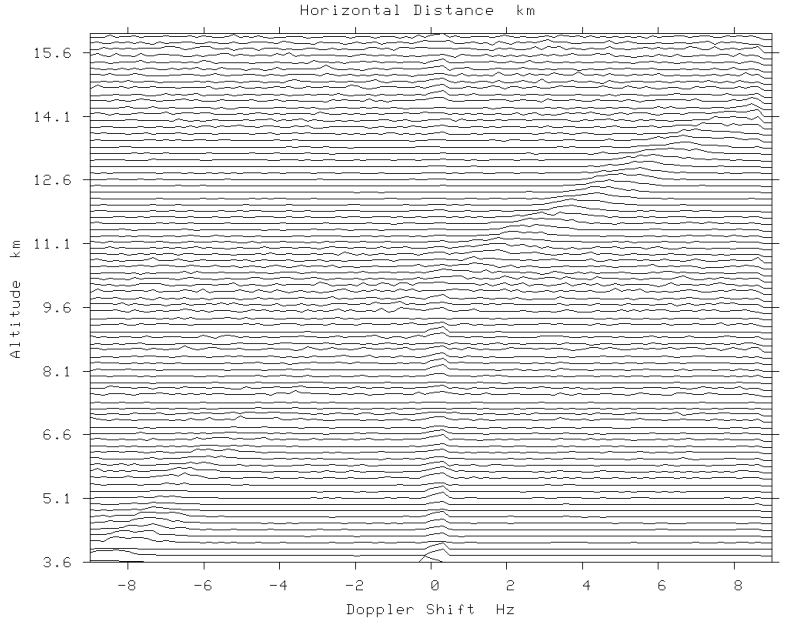

Fig. 9. (a) Result of ray tracing as in Fig. 8 for NS-plane on 23 July 2006; time of launch of radiosonde 17:52 UTC; (b) Power spectrum of $Z x$ antenna beam (15:51:17 LT).

It is noteworthy that the RASS observations with the Gadanki MST radar have a great potential to continuously measure temperature profiles in the entire troposphere above about $2 \mathrm{~km}$. In a future experiment with additional acoustic transmitters, it is hoped to expand the RASS height range up to about $22 \mathrm{~km}$, which was achieved with the MU radar in Japan by employing a similar configuration, i.e. a VHF wind profiler with the similar sensitivity and the same type acoustic horns. This is inspite of the limited azimuthal beam steering capability of Gadanki $\left(90^{\circ}\right.$ step) compared to that of MU radar ( $5^{\circ}$ step) and maximum tilt angle for oblique beams; which are $20^{\circ}$ and $30^{\circ}$, respectively. There are a number of important subjects in the upper troposphere and lower stratosphere (UTLS) region in the tropics, such as time-height variations of water vapor, transport and mixing of minor constituents and generation and propagation of atmospheric waves. The RASS at Gadanki will be capable of clarifying these processes.

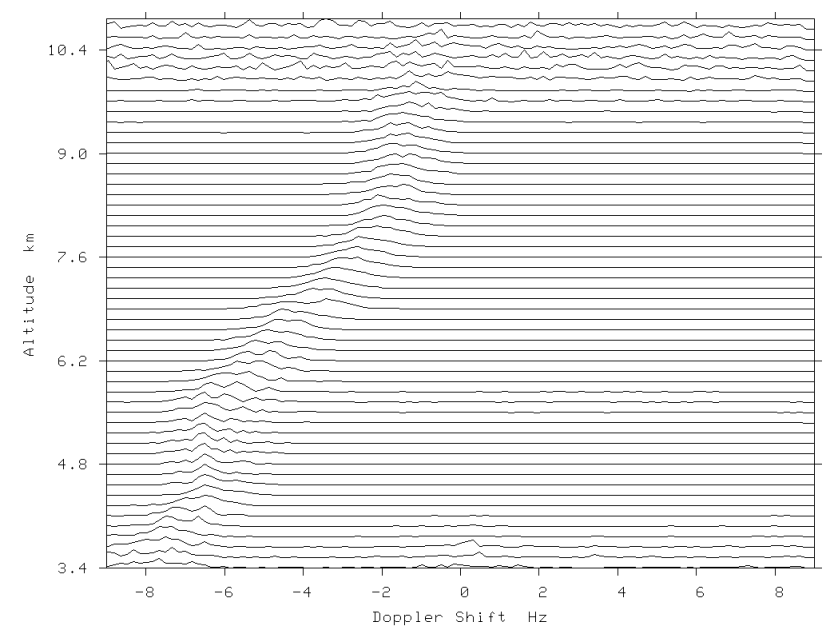

Fig. 10. Power spectrum of backscattered echo from acoustic wavefronts showing double-humped spectrum at a few range gates recorded along beam $20^{\circ} \mathrm{W}$ on 23 July 2006 (17:42:35 LT).

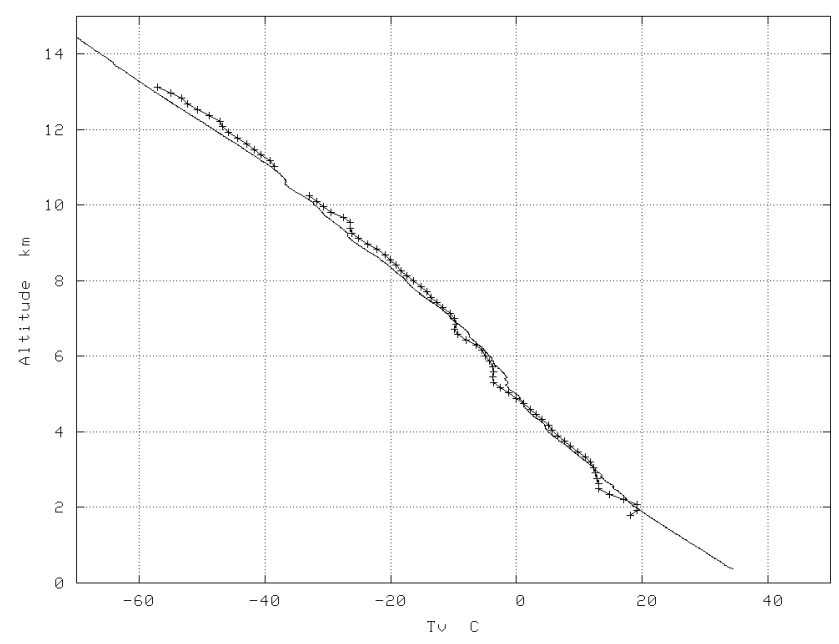

Fig. 11. A comparison of virtual temperatures derived from the data of 23 July 2007 (crossed) and radiosonde.

Figure 15 shows the deviation of the $T_{v}$ derived from RASS compared to the radiosonde results. The r.m.s. deviation between the two temperature profiles ranges about $1 \mathrm{~K}$ upto about $8 \mathrm{~km}$. However, some large discrepancy was recognized which is of the order of about $3 \mathrm{~K}$ in Fig. 14, probably because of a poor estimation of the background radial wind velocity, which should be subtracted from the apparent sound speed before converting it to temperature.

\section{Conclusion}

In this paper, development of a pilot RASS system with Gadanki MST radar $(53 \mathrm{MHz})$ was described. Design aspects 


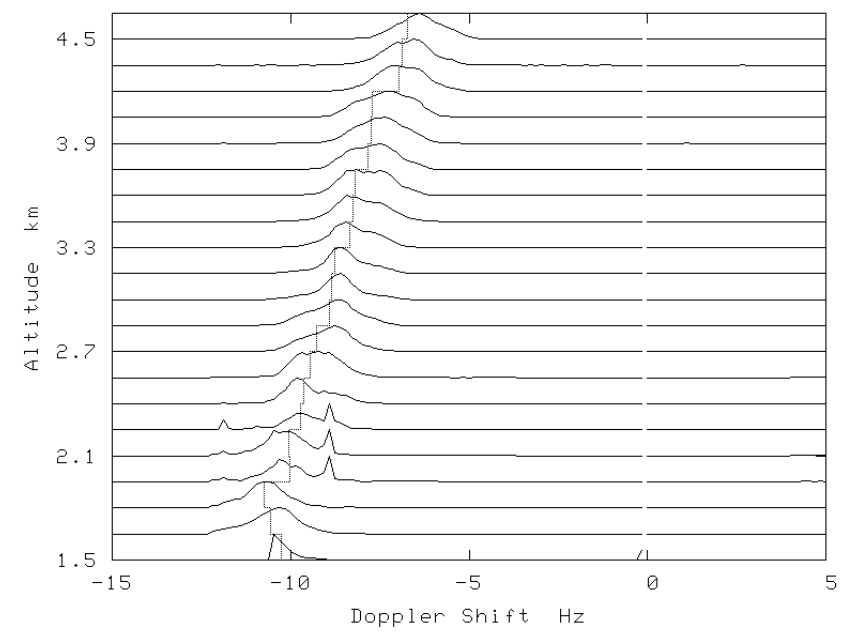

Fig. 12. Spectrum of acoustic echo. Mean Doppler shift by moments method is shown by vertical dotted lines for each range bin.

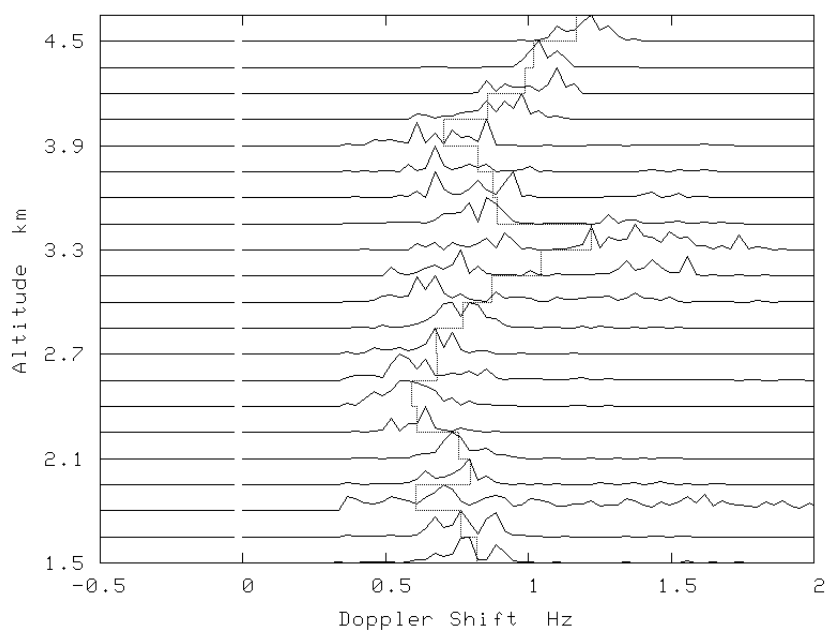

Fig. 13. Spectrum of turbulence echo with beam $20^{\circ} \mathrm{W}$. Mean Doppler shift by moments method is shown by vertical dotted lines for each range bin.

and performance measurements of the acoustic attachment that was developed and operated have been detailed.

In order to satisfy Bragg matching condition over a temperature range of $-90^{\circ}$ to $40^{\circ} \mathrm{C}$, the required acoustic frequency range is $94-125 \mathrm{~Hz}$. Acoustic signal generation is done using a commercial Ethernet controlled audio player. Acoustic exciter consists of an approximation to hyperbolic horn, subwoofers and associated power amplifiers. FMCW chirp signals were transmitted at $140 \mathrm{~dB}$ SPL in this frequency range.

The RASS system was operated on several occasions between May and August 2006. During 23-24 July 2006, RASS echoes were obtained continuously for about $18 \mathrm{~h}$. RASS and wind modes were interleaved at intervals of about $25 \mathrm{~min}$. On the average, echoes were obtained from $1.5 \mathrm{~km}$

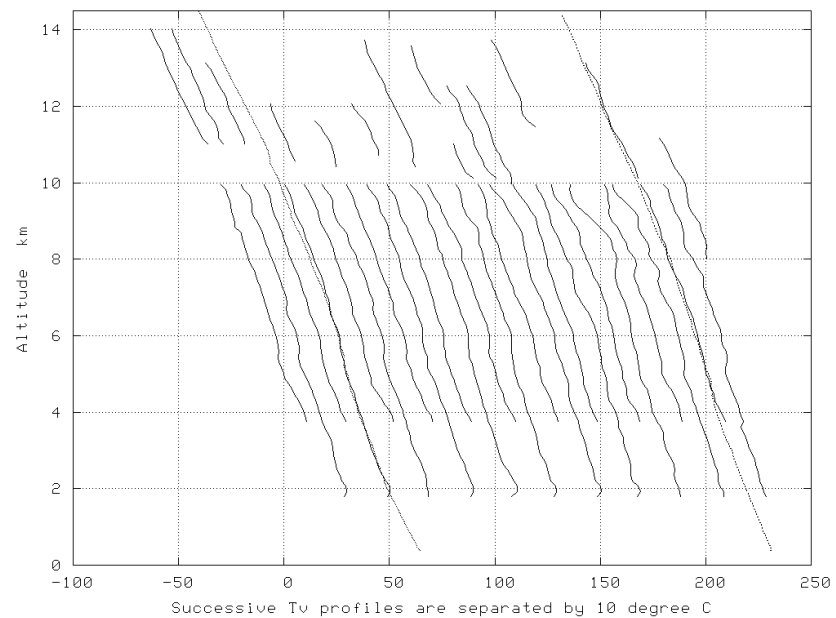

Fig. 14. Height profiles of $T_{v}$ from RASS observations of 23-24 July 2006. Individual profiles are separated by about $25 \mathrm{~min}$. Two radiosonde results are shown in dotted lines.

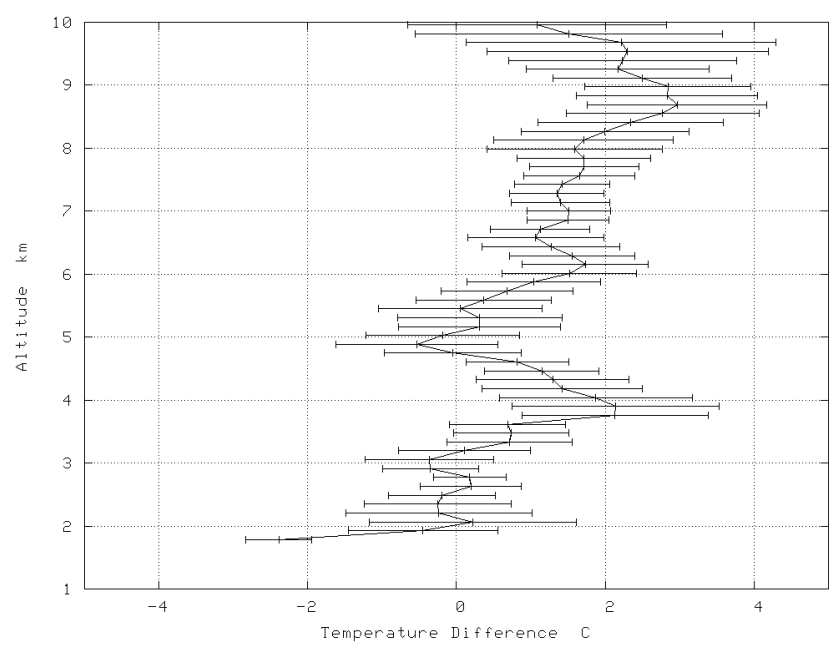

Fig. 15. Mean deviation of RASS $T_{v}$ of Fig. 14, with respect to mean radiosonde $T_{v}$ values.

to $10 \mathrm{~km}$ in altitude and occasionally up to $14 \mathrm{~km}$. Mean Doppler shift of the acoustic echoes and turbulence echoes were obtained by computing the moments of the power spectrum. Altitude profiles of atmospheric virtual temperature were computed after correcting for background mean wind interpolated from observations separated by about $25 \mathrm{~min}$. In this period three GPS radiosondes were launched at about 6-hourly interval. Comparison between the RASS and radiosonde virtual temperature is shown.

In comparison with the two simultaneous radiosonde launches, RASS derived temperature profiles had the r.m.s. discrepancy of about $1 \mathrm{~K}$, although deviation of the RASS results sometimes appeared when the radial wind velocity was not fully available for the correction of apparent sound speed. 
During several other experiments the range of RASS echoes was limited due to background wind conditions. Ray tracing was applied to predict the optimum antenna beam directions for RASS echoes along the EW and NS planes using wind and temperature data from radiosonde launches. In order to overcome the inflexibility imposed by the antenna beam steering capability and to counter the effect of horizontal wind, it is planned to deploy several acoustic sources along the NS and EW baselines and also along the diagonal directions as shown in Fig. 3, and excite them as required.

The successful demonstration of the RASS application with Gadanki MST Radar is expected to be used for continuous observations of the temperature profiles in the troposphere and lower stratosphere regions. Continuous monitoring of temperature profiles at this tropical latitude would provide rich information on local atmospheric phenomena as it witnesses varied atmospheric events.

Acknowledgements. This work was supported by experimental projects support grant of National Atmospheric Research Laboratory, Gadanki, which is a grants-in-aid institution of Dept of Space, Govt. of India.

The authors would like to acknowledge the help of Ranjan Moodithaya of National Aerospace Laboratories, Bangalore in the measurement of parameters of acoustic horns.

The first author acknowledges the support provided by Japan Society for the Promotion of Science, Govt. of Japan, by way of RONPAKU (dissertation PhD) fellowship to cover the research visits to RISH, Kyoto University, Japan. The study is partially supported by Grants-in-Aid for Scientific Research (B) 18340140.

The authors would like to thank the anonymous reviewers for their detailed comments that helped in improving the content.

Topical Editor U.-P. Hoppe thanks two anonymous referees for their help in evaluating this paper.

\section{References}

Adachi, T.: Detailed Temperature Structure of Meteorological Disturbances Observed with RASS, Ph.D. thesis, Kyoto University, Kyoto (Japan), 1996.

Alexander, S. P., Tsuda, T., and Furumoto, J.: Effects of Atmospheric Stability on Wave and Energy Propagation in the Troposphere, J. Atmos. Ocean. Technol., 24, 602-615, 2007.

Balsley, B. B. and Gage, K. S.: The MST Radar Technique: Potential for Middle Atmospheric Studies, Pure Appl. Geophys., 118, 452-493, 1980.
Bonino, G., Lombardini, P. P., and Trivero, P.: A meric wave radioacoustic tropospheric sounder, IEEE Transactions on Geoscience Electronics, GE-17(4), 179-181, 1979.

Clifford, S. F., Kaimal, J. C., Lataitis, R. J., and Strauch, R. G.: Ground-based remote profiling in atmospheric studies:an overview, Proc. IEEE, 82, 313-355, 1994.

Hildebrand, P. H. and Sekhon, R. S.: Objective determination of the noise level in Doppler spectra, J. Appl. Meteor., 13(7), 808-811, 1974.

Kon, A. I.: A bistatic radar-acoustic atmospheric-sounding system, Izvestiya - Atmospheric and Oceanic Physics, 17(6), 481-484, 1981.

Makarova, T. I.: Measurement of temperature profiles in the surface layer of the atmosphere by radar-acoustic sounding, Izvestiya Atmos. Ocean. Phys., 16(6), 453-455, 1980.

Marshall, J. M., Peterson, A. M., and Barnes Jr., A. A.: Combined radar-acoustic sounding system, Appl. Opt., 11, 108-112, 1972.

Masuda, Y.: Influence of wind and temperature on the height limit of a radio acoustic sounding system, Radio Sci., 23, 647-654, 1988.

Matuura, N., Masuda, Y., Inuki, H., Kato, S., Fukao, S., Sato, T., and Tsuda, T.: Radio acoustic measurement of temperature profile in the troposphere and stratosphere, Nature, 323, 426-428, 1986.

May, P. T., Strauch, R. G., Moran, K. P., and Ecklund, W. L.: Temperature sounding by RASS with wind profiler radars: A preliminary study, IEEE Trans. Geosci. Rem. Sens., 28, 19-28, 1990.

Olson, H. F.: Acoustical Engineering, 738 pp, D. Van Nostrand Company, Inc., Princeton, New Jersey, 1957.

Peters, G., Hasselmann, D., and Pang, S.: Radio acoustic sounding of the atmosphere using a FM CW radar, Radio Sci., 23, 640646, 1988.

Rao, P. B., Jain, A. R., Kishore, P., Balamuralidhar, P., Damle, S. H., and Viswanathan, G.: Indian MST radar 1. System description and sample vector wind measurements in ST mode, Radio Sci., 30, 1125-1138, 1995.

Tsuda, T., Adachi, T., Masuda, Y., Fukao, S., and Kato, S.: Observations of Tropospheric Temperature Fluctuations with the MU Radar-RASS, J. Atmos. Ocean. Technol., 11, 50-62, 1994.

Warshaw, S. I.: On a finite amplitude extension of a geometric acoustics in a moving, inhomogeneous atmosphere, UCRL53055, Lawrence Livermore Laboratory, University of California, Livermore(USA), 1980.

Woodman, R. F.: Spectral moment estimation in MST Radars, Radio Sci., 20, 1185-1195, 1985.

Woodman, R. F. and Guillen, A.: Radar observations of winds and turbulence in the stratosphere and the mesosphere, J. Atmos. Sci., 31, 493-505, 1974. 